
\title{
28 Research Square \\ Predicting the students' learning behaviour for a technical course during Covid-19
}

Dr. Ishwar Dutt

Chitkara University, Himachal Pradesh

Dr. Ashu Taneja ( $\square$ ashu.taneja@chitkarauniversity.edu.in )

Chitkara University, Himachal Pradesh https://orcid.org/0000-0002-6468-3686

\section{Dr. Ajay Sharma}

Chitkara University, Himachal Pradesh

\section{Research Article}

Keywords: Offline interaction, classroom teaching, Covid-19, teaching-learning, Online teaching

Posted Date: October 23rd, 2020

DOI: https://doi.org/10.21203/rs.3.rs-97063/v1

License: (1) This work is licensed under a Creative Commons Attribution 4.0 International License. Read Full License 


\section{Abstract}

The purpose of this paper is to analyse the learning behaviour of students towards a technical course using online mode and offline mode. Due to the outbreak of Covid-19 pandemic, the educational fraternity has successfully reached out to the students using the various virtual tools available. Although, the offline mode of teaching-learning i.e. the actual classroom interaction is quite important as far as a technical course is concerned, but during these tough times the online platforms like Zoom, Webex meetings, Google meet have made the teaching-learning feasible remotely at any time from any place. This paper compares the learning behaviour of students in the two modes, online mode, and offline mode. A total of 213 students studying a technical course participated in the survey and their responses based on a questionnaire were recorded. The questionnaire considered all aspects related to the delivery of contents, the evaluation method, the preferred way of clarifying students' doubts, course difficulty level and duration of the course. The analysis suggests that $72.3 \%$ of students are in favour of learning this course using offline mode, while $27.7 \%$ of students are comfortable with online mode. Furthermore, the present study reveals that $95.7 \%, 95.3 \%$, and $75.1 \%$ of students are congenial with the offline mode in terms of teacher competency, content delivery, and interaction possibility respectively, whereas $85 \%$, $76.9 \%$ and $48.4 \%$ of students are congenial with the online mode in terms of same parameters. The higher magnitude of average mean value for offline mode (3.99) anticipates its dominance over online mode (3.18). More than $50 \%$ students favoured online mode along with multiple choice question papers for the evaluation process irrespective of their preference to offline mode for teaching-learning. Based on the present analysis, some recommendations are proposed as the future strategies to improve the performance of teaching-learning activities during the times of crisis.

\section{Introduction}

Covid-19 pandemic has led to the indefinite closure of educational institutions all across the world. This results in multiple new challenges in terms of sustaining the education for policymakers, administrators, teachers, and particularly for students. The continuation of the syllabus, students' assessment and scheduling of exams are very important in this crisis period till the classroom activities resume. So, to compensate for the classroom teaching-learning loss caused by the interruption of classroom learning due to the lockdown, the Ministry of Education (MoE) has taken the initiative to use online modes for teaching-learning [1]. Finch and Jacobs [2] defined online mode of teaching-learning as "all forms of teaching and learning where the student and instructor are separated geographically and temporally". The role of information technology is vital in bridging this gap [3]. The online education guidelines prompt the use of e-learning by conducting online e-learning sessions with students using several applications. The MoE ministry is running several online platforms for learning like, SWAYAM (study webs of active learning for young aspiring minds), NPTEL, COURSERA, Diksha, e-pathshala, NROER (National Repository of Open Educational Resources), NIOS (National Institute of Open Schooling) and other IT 
initiatives e-yantra (robotics education), FOSSEE (open source software for education), virtual labs and spoken learning programmes.

Through the repository of thousands of online courses, it is being ensured that the learning of students continues even during the lockdown period. It is seen that in the lockdown period, the number of subscribers to these online learning portals has increased many-fold [4]. The MOOC (Massive open online courses) is another initiative towards virtual learning [5]. Since then, the directives of the regulators like NCERT, UGC, AICTE, Directorate of Higher Educations have been implemented by schools and higher education institutions. The virtual classes are being held using several online platforms like Zoom, Google meet, Webex meetings, Skype meet up, Google classrooms. To ensure that the process of teaching-learning is not hampered due to the closure of schools and universities, online learning is the only means. Online learning or e-learning is a tool that is more flexible, innovative, and student-centric [6]. All you need a device that is connected to a network and you can learn from any place at any time at your own pace. Online learning experiences are categorised as synchronous learning or asynchronous learning environments. In synchronous learning environment, the students can attend the live sessions and interact with the instructor [7]. While in asynchronous learning environment, instant feedback is not possible because it is not properly structured [8]. So, the need of the hour is to have the online platforms which provide access to video-conferencing with 40-50 students, can get feedback from students, can hold discussions with students, can support mobile phones but not only laptops. The e-learning environment needs to be designed in a user-friendly way such that in an emergency like Covid -19, quality education can be provided to the students [9].

On similar lines, the challenges with these online modes of teaching and learning cannot be neglected. Kebritchi et al. [10] highlight the challenges of online teaching for higher education. The technology adaption is one. The ease of understanding the concept being taught is another aspect. The online assessment of students is another challenge being faced by the regulators and teaching faculty. Internet connectivity and network reliability are unforgettable. The long term effects of exposure to the computer screen for long hours due to online classes is leading to certain vision problems in children.

In this paper, the effects of Covid -19 on the learning behaviour of students for a technical course, Modern and Computational Physics, is evaluated. This course includes the fundamental concepts of lasers, fibre optics, magnetic properties of materials, superconductivity, and global positioning system (GPS) along with computational programming. The students' perception of learning this course via online mode and offline mode during Covid-19 is predicted. An online questionnaire was circulated among the undergraduate students studying this course. The responses were received from around 213 students. The comparison between the two teaching-learning methods, viz., face-to-face classroom teaching and virtual online teaching is presented based on factors such as ease of understanding the subject matter, teachers' competency, delivery of contents and students' comfort level. The ways by which studentteacher interaction can be improved in online mode also discussed. The feedback is also taken from students to improve the quality of online teaching for this course. The students' responses about their requirements for the study materials doubt clearing assistance are also taken into account. The 
important factors like difficulty level of the course, the duration of the online class and their interest in learning the course are also given due consideration while evaluating the students' behaviour. The responses related to the mode of evaluation of the course and the pattern of the questions paper to be set for this course have also been recorded.

\section{Literature Survey}

In the literature number of studies reported the introduction of online teaching-learning for education sustainability in versatile domains.

Balasopoulou et al. [11] conducted a similar study of online teaching-learning methodology for ophthalmology. The COVID-19 crisis has started a new wave of e-learning in ophthalmology. Using online resources, how ophthalmologic education can be sustained and made interesting for the students. Also, the challenges associated with making ophthalmologic learning online are addressed. Agarwal and Kaushik [12] highlighted the same for entrepreneurship education which is hit hard by the COVID crisis. The need for scholarships and development of additional online resources is emphasized in their work. The induction of online teaching in medical education mainly for pediatric resident training is investigated in [13]. The responses were taken from resident doctors and their learning behaviour is evaluated. To continue the delivery of education, students' perceptions are recorded to find whether online classes can be added in the medical curriculum or not [14]. The comparative analysis of students' efficiency is carried out in [15] for the students who study online courses relative to the students who study through face-to-face offline classroom teaching methods. Martin [16] provides five key points for the educators that are necessary for optimizing the online teaching during the corona pandemic. According to the author, motivation is one of the important key points. It is necessary to keep motivating the students such that their mental health does not suffer. A good interpersonal relationship is a must for a successful learning. The analysis of strengths, weaknesses, opportunities and threats (SWOT) for introducing e-learning into the university curriculum is performed in [17]. The measures to overcome the threats and weaknesses are provided and the strengths are adopted for the learning to continue. Parkes et al. [18] have investigated the preparedness level of the students for the e-learning environment. The familiarity with the digital tools and ease of accessing the virtual platforms is evaluated by employing a survey. Favale et al. [19] have analyzed the variations in traffic patterns of university campuses while shifting to e-learning solutions amid lockdown due to the Covid pandemic. The robustness of internet plays an important role in carrying out university operations. It has been observed that the university einfrastructure is serving around 16000 students by scheduling 600 classes on daily basis. For shifting from the traditional classroom teaching to online teaching, Basilaia [20] studied and compared the available products of google, namely, Gmail, Classroom, Drive, Meet, Calendar and Forms in order the prepare the university for the online learning environment. All the features of these services were successfully tested for further implementation.

In the literature, there are researchers, who analysed the impact of natural disasters on the performance of students. Pietro [21] has examined the impact of L'Aquila earthquake that shook Italy in 2009 on the 
students' academic performance. It has been analysed that due to disruptions in the learning environment, the probability of student dropouts is more. The effects of school closures post-earthquakes on the education delivery system described by Shiwaku and Shaw [22]. The authors have emphasized the role of information and communication technology (ICT) to support the continuity of education in situations of natural calamities. Online teaching-learning support is promoted and ways to strategize this are also highlighted. Wilkinson et al. [23] has evaluated the performance of medical students after the disruption of learning environment post two earthquakes which took place in different quarters of the academic year. The paper [24] analysed the adaption of e-learning technology after an earthquake hit New Zealand in 2011. The case study of a business school is considered and how it has continued the teaching-learning process with a new technological model post-earthquake. After an extensive literature survey, it is clear that the information and communication technology (ICT) plays an important role to continue the teaching-learning process in times of natural calamities, disasters and pandemic.

\section{Materials And Methods Used}

As per the academic calendar of our institute, the even semester commences in January and as usual, the regular face to face classroom teaching method was already operational for the course "Modern and Computational Physics". The Covid-19 pandemic and consequent lockdown led to the indefinite closure of all the institutions in our country in March 2020. The biggest challenge was the sustainability of the education in this difficult time. Therefore, online teaching also called emergency virtual teaching has come to the rescue of the educational institutions, teaching fraternity and students. Few short-term Faculty Development Programmes (FDPs) and Workshops were organised by the institute before its shutdown to train academic staff about the utilization of various online platforms such as GoTo Webinar, GoTo Meeting, Zoom, Cisco Webex Meetings, Google Meet etc. to deliver the remaining course content. Using above online platforms, lectures were scheduled every day of one-hour duration. After online class, a recorded lecture supplemented with e-learning material was shared with students on the institute ERP platform (Chalkpad). Instructor tried to clear all doubts of students through live chat, WhatsApp or email. Online platform (MyAnatomy) was used to conduct remaining Internal Evaluation Components (IECs), Sessional Tests (STs) and End Term Examination (ETE). Online mode of teaching-learning has replaced the face-to-face classroom teaching during these tough times. But here the biggest stakeholders are the students and their feedback is very important as far as the teaching-learning is concerned. In this paper, students' perceptions in terms of certain questionnaires are recorded and their learning behaviour for a technical course "Modern and Computational Physics" via online mode and offline mode is analysed. The results of the analysis are presented in the next sections.

\section{Results And Discussion}

Effect of COVID-19 on Teaching-Learning Process:

Students' perception (SP) and comfort level (CL) about online and offline mode of teaching: 
The recorded responses of students' perception (SP) and their comfort level (CL) with online and offline modes of teaching are plotted against a five-point scale [25] in figure 1. Here, SP and CL include their adaptation to the two modes which depend on many factors viz. availability of learning resources, wellequipped technical support along with the students' interest in learning the course.

Firstly, in the case of SP, out of 213 students in our sample, $35.7 \%$ and $36.6 \%$ responses are respectively agreed and strongly agreed with offline mode. $24.4 \%$ students are neutral and very few (1.4\% disagree and $1.9 \%$ strongly disagree) are not congenial with offline mode (blue cylindrical column). On the other hand, $25.8 \%$ and $7.5 \%$ students responded respectively that they are agreed and strongly agreed with online mode. Whereas, $39.9 \%$ students are neutral and rest (17.8\% students disagree and $8.9 \%$ strongly disagree) are disagreed with this mode (orange cylindrical column).

In the case of comfort level (CL), $34.7 \%$ and $27.7 \%$ of students are respectively agreed and strongly agreed or feel comfortable with offline mode of teaching this course. According to responses recorded, $32.4 \%$ of students are neutral and only a few (3.3\% disagree and $1.9 \%$ strongly disagree) not congenial with offline mode (gray cylindrical column). On the other hand, $34.3 \%$ and only $9.4 \%$ students are agreed and strongly agreed, whereas, $37.1 \%$ students and remaining $(10.8 \%$ disagree and $8.0 \%$ students strongly disagree) have disagreed with this mode (yellow cylindrical column).

From the above results it is clear that 154 (72.3\%) students favoured the offline mode, while $59(27.7 \%)$ of students favoured online mode of teaching. Also, 133 (62.44\%) students feel more comfortable if they learn this course through offline mode. Since the online mode of teaching-learning was introduced all of a sudden due to the pandemic outbreak, the students' find it tough to adapt to this new system of learning. Moreover, many factors affected their online learning experiences such as poor internet connectivity, limited data plans, power cuts, and other infrastructure required. Further, 25 to $40 \%$ of students are undecided because firstly, they were unprepared for this kind of learning transformation, and secondly, they have no clue how long will this ongoing pandemic situation persist. They are not able to make out how to balance their work, health and social lives with the new online classwork environment [18].

Regarding interaction with students (IwS), the recorded students' responses are plotted in figure 2. In this case, $34.7 \%$ and $40.4 \%$ students responses favor the frequently and always possibility of interaction during offline mode of teaching respectively. Whereas, $20.7 \%$ and only $1.9 \%$ students are of the view that the interaction was occasionally and rare respectively. Very few students $(2.3 \%)$ are of the view that during offline mode there is no possibility of any interaction with teacher (blue shaded area). On the other hand, $26.3 \%$ and $10.3 \%$ students are of the view that interaction occurs frequently and always during the conduct of online class respectively. Whereas, $37.6 \%$ responded to occasionally teacher's interaction and $12.7 \%$ students viewed about rare interaction. Further, $13.1 \%$ students pointed out that there is no possibility of interaction during online mode (orange shaded area).

From the above facts, it can be inferred that there is more possibility of interaction in offline mode $(75.1 \%)$ of teaching as compared to online mode (48.4\%). This is because the face-to-face classroom 
teaching-learning provides the flexibility of asking queries instantly and get the same resolved by the instructor at the same moment making no room for doubts. Moreover, students learn more easily while discussing, practicing or learning by doing with peers and instructors in actual classroom conditions. Whereas in online mode, this kind of instant interaction with the tutor and live practice is difficult for several reasons already listed in the previous section. Recently, Holbeck \& Hartman [26] suggested some technical tools such as Flipgrid, Digital Breakout/ Escape Room, Loom and Remind to achieve maximize online students satisfaction.

\section{Teacher competence (TC) and content delivery (CD) during online and offline mode of teaching:}

Teacher competence (TC) and content delivery (CD) are other parameters that are considered while analysing the offline and online mode of teaching, the responses of students recorded are plotted in figure 3.

Regarding TC, $23 \%, 39.4 \%$ and $33.3 \%$ students responded respectively about good, very good, and excellent TC level during offline mode. Very few $1.4 \%$ and $2.8 \%$ students viewed that TC was fair and poor respectively (blue rectangular column). On the other hand, $36.6 \%, 29.6 \%$ and $18.8 \%$ students responded the TC was good, very good and excellent respectively. Whereas $10.3 \%$ and $4.7 \%$ students perceived that teacher competence was fair and poor during online mode respectively (orange rectangular column).

When asked about CD, it was recorded that $21.6 \%, 40.8 \%$ and $32.9 \%$ students' responses favour good, very good and excellent level of CD during offline mode of teaching respectively. Only few $(3.3 \%$ and $1.4 \%$ ) students' favour fair and poor level respectively (gray rectangular column). On the other hand, $39 \%$, $29.6 \%$ and $11.3 \%$ students' favour good, very good and excellent level of content being delivered during online mode respectively. Whereas, $13.1 \%$ and $7 \%$ students' favour respectively fair and poor CD level during same mode (yellow rectangular column).

Therefore, above facts clearly favoured the better TC level (95.7\%) of teacher during offline mode of teaching as compared to online mode (76.9\%). Also, $95.3 \%$ students are satisfied with offline mode as far as CD is concerned. It is quite obvious that if a teacher is asked to switch to a less familiar mode immediately to deliver the remaining content, the proportional students' satisfaction may not be achieved. Similarly, in online CD mode teachers may not be able to resonate with students due to physical separation and monotonous teaching platforms with limitations.

The five-point scale selected to students' responses against SP, CL, IWS, TC and CD is tabulated in Table 1.

Table 1. The five-point scale related to student response against parameters taken into account for making the choice between online and offline mode of teaching 


\begin{tabular}{|l|l|l|l|l|l|}
\hline \multirow{2}{*}{$\begin{array}{l}\text { Responses } \\
\text { Against }\end{array}$} & \multicolumn{5}{|c|}{ Five Point Scale } \\
\cline { 2 - 6 } & 1 & 2 & 3 & 4 & 5 \\
\hline SP & $\begin{array}{l}\text { Strongly } \\
\text { disagree }\end{array}$ & Disagree & Neutral & Agree & $\begin{array}{l}\text { Strongly } \\
\text { agree }\end{array}$ \\
\hline CL & $\begin{array}{l}\text { Strongly } \\
\text { disagree }\end{array}$ & Disagree & Neutral & Agree & $\begin{array}{l}\text { Strongly } \\
\text { agree }\end{array}$ \\
\hline IwS & Never & Rarely & Occasionally & Frequently & Always \\
\hline TC & Poor & Fair & Good & Very Good & Excellent \\
\hline CD & Poor & Fair & Good & Very Good & Excellent \\
\hline
\end{tabular}

Further, the mean value of responses recorded is plotted in figure 4. Interestingly, the higher magnitude of the mean value corresponds to offline mode, clearly indicate its preference over online mode. The average mean value for offline (3.99) mode has an upper edge over the and online (3.18) mode as depicted in figure 4.

\section{Type of Study Material and Doubt Clearing Assistance Provided During Online Teaching:}

As explained in section materials and methods used, about the study material uploaded on the university ERP platform and preferred ways to clarify students doubts, the corresponding responses are recorded in Table 2. It is clear from table 2 that $176(82.6 \%)$ students responded that the material supplied with online teaching mode must be a combination of video lectures supplemented with relevant study material. This clearly indicates that majority of students need a more in-depth explanation to better understand the concepts and prepare themselves for evaluation. Only $10.8 \%$ and $6.6 \%$ students favour the sufficiency of only reading and video material respectively.

Table 2. The number of students' responses related to nature of study material provided along with the preferred way to clarify their doubts during online mode of teaching.

\begin{tabular}{|l|l|l|l|}
\hline $\begin{array}{l}\text { Nature of study material } \\
\text { provided }\end{array}$ & $\begin{array}{l}\text { No of } \\
\text { Students } \\
(\%)\end{array}$ & $\begin{array}{l}\text { Ways adopted to clarify } \\
\text { students' doubts }\end{array}$ & $\begin{array}{l}\text { No } \\
\text { Students } \\
\text { (\%) }\end{array}$ \\
\hline Reading material is sufficient & $23(10.8 \%)$ & Live chat & $20(9.4 \%)$ \\
\hline $\begin{array}{l}\text { Video content supplemented } \\
\text { with reading material }\end{array}$ & $\begin{array}{l}176 \\
(82.6 \%)\end{array}$ & $\begin{array}{l}\text { Both live chat and email to } \\
\text { the course }\end{array}$ & $\begin{array}{l}113 \\
(53.1 \%)\end{array}$ \\
\hline Video content is sufficient & $14(6.6 \%)$ & WhatsApp & $67(31.5 \%)$ \\
\cline { 3 - 4 } & & Offline & $13(6 \%)$ \\
\hline
\end{tabular}

To clarify students doubts during online teaching mode, the ways adopted were live chat, Email, WhatsApp, and offline. When asked to respond about that $53 \%$ students favour the both live chat and email to the course instructor option, $32 \%$ favour WhatsApp, $9.4 \%$ live chat and remaining opt the offline option to clarify their doubts.

Therefore, during online mode, majority are satisfied with video content supplemented with reading material and their maximum doubts are clarified with both live chat and email to the course instructor. 
The video content gives clarity to the concept and the reading material helps the students to make notes for exams and evaluations.

\section{Class Duration During Online Mode of Teaching:}

When asked about duration of online class, majority (57.7\%) of students reported about 45 minutes, $27.7 \%$ about one hour, $13.6 \%$ students about 30 minutes and only $1 \%$ students favoured more than 1 hour class duration related to this course. This indicates that $45 \mathrm{~min}$ to 1 -hour class duration is sufficient for healthy teaching-learning in terms of content discussion and mental focus of students especially during the time of crises.

\section{Difficulty Level and Interest of Students in Studying this Course:}

It is important to understand learners' interest and difficulty in learning Modern and Computational Physics. The recorded responses are presented in figure 5.

When asked about their interest, $39.4 \%$ and $13.6 \%$ students found the course very much and extremely interesting. Whereas, 35.2 and $7 \%$ students are moderately and slightly interested in learning this course and remaining $(4.7 \%)$ students are not interested at all (green bars).

In view of difficulty level, only $96(45.1 \%)$ students found it moderate, whereas $36.6 \%$ and $3.3 \%$ students found it hard and very hard respectively. Whereas, $12.2 \%$ and $2.8 \%$ students found this course easy and very easy respectively (orange bars).

From the above discussion it is clear that, around $40 \%$ students found this course difficult with mean score magnitude 3.25. At the same time, it is interesting to note that majority of the students (more than $50 \%$ ) are also interested to learn this course with a mean value 3.50. As it is clear from figure 3 that TC and $C D$ in case of offline mode are much better as compared with online mode. Therefore, the probable reasons for difficulty and lesser interest may be (i) the prevailing situation (ii) online mode (iii) lesser magnitude of TC and CD during online class (iv) lack of fundamental concepts clarity (v) lack of classroom/lab practice for understanding the theoretical concepts (vi) no group learning as the online mode is completely individual-centric. In the following sections, mode of evaluation is discussed.

\section{Mode of Evaluation}

To judge the outcome of any teaching-learning activity, evaluation plays a central role. Nowadays both online and offline mode of evaluation gains popularity in engineering as well as scientific disciplines all over the globe [27][28]. Since due to social distancing, only online mode was possible to conduct the evaluation process. Still, the responses were recorded and listed in table 2 to know students perception and to further improve the evaluation process. In the case of evaluation, $50.7 \%$ of students favour online mode, $31 \%$ students favour both online and offline and only $18 \%$ students favour offline mode of evaluation related to this course. 
Table 3. The number of responses of students related to mode of evaluation and pattern of question paper for Modern and Computational Physics.

\begin{tabular}{|l|c|l|c|}
\hline $\begin{array}{l}\text { Mode of } \\
\text { evaluation }\end{array}$ & $\begin{array}{c}\text { No of Students } \\
\text { (\%) }\end{array}$ & Pattern of question paper & $\begin{array}{c}\text { No of Students } \\
\text { (\%) }\end{array}$ \\
\hline Offline & $39(18.3 \%)$ & Multiple choice type (MCQs) & $156(73.2 \%)$ \\
\hline Online & $108(50.7 \%)$ & Descriptive type only & $2(1 \%)$ \\
\hline $\begin{array}{l}\text { Both offline \& } \\
\text { online }\end{array}$ & $66(31 \%)$ & $\begin{array}{l}\text { Combination of MCQs and } \\
\text { descriptive type }\end{array}$ & $55(25.8 \%)$ \\
\hline
\end{tabular}

When asked about pattern of question paper, $73 \%$ students replied that it must be a multiple choice type, $26 \%$ students favour combination of multiple choice and subjective type and only $1 \%$ students responded to the subjective type.

Therefore, from these facts it can be inferred that majority (more than 50\%) of students favour online mode for the evaluation of this course along with multiple choice question paper type irrespective of their preference to offline mode for learning the same course.

Though the students' concepts become more clear in classroom interaction with the teacher in offline class, as students may feel more involved in the subject in offline teaching as compared to the online mode of content delivery. But as far as evaluations are concerned, the students prefer to appear for online and MCQ evaluations as compared to offline examinations. This seems to have some correspondence with their comfort level in MCQ and online evaluations. Since MCQs have the limitation to cover all course learning outcomes (CLO) with the perspective of Bloom's taxonomy. Students find it quite easy to attempt MCQ based upon lower levels of difficulty instead of writing/drawing/deriving long text/figures/equations in case of subjective (offline) evaluations. Moreover, in some cases lack of proper proctoring is another reason why students prefer online mode of assessment as the assessment is carried out in their own environment or personal space. Hollister et al. [29] has also reported that students appearing in online examinations have more variations in their results as compared to the offline evaluations conducted in a proctored environment.

\section{Conclusions And Suggestions}

This paper presents the comparison of online versus offline mode of teaching due to social distancing and lockdown conditions imposed due to COVID-19 pandemic on "Modern and Computational Physics" course offered to first year students at our institution. We have considered 250 students studying this course, only 213 responded to the questionnaire shared with the help of Google form. While designing questionnaire, main focus was on teaching learning process, students' interest and difficulty level in 
studying this course along with duration and evaluation process. Based on the responses recorded, more than $70 \%$ students favoured offline mode over online (just 33\%) mode. Further, the interaction of teacher with students, teacher competency, comfort level of students and content delivery by teacher during offline mode is much better as compared to online mode. Since India reached at second position with total $66,85,082$ cases and 103,569 death [30]. Therefore, in the current situation, online mode is a boom to sustain the teaching-learning process with following suggestion:

- Instructor needs to explore full potential in utilizing online platform so as make their presentation more realistic.

- Teachers and students both have to be made familiar with online teaching and assessment in an ideal way.

- More discussion is required during online mode to make teaching more organic.

- Since the level of difficulty is more as per students' perception, so more doubt clearing sessions should be organized for better concept clarity.

- Class size should be reduced to 30-40 maximum for effective online interaction.

- The instructor should be extra cautious in reporting any mental health issues faced by the student as happy learning is effective learning.

- Students should have access to all online technology.

- The instructor should explore some innovative teaching methods in online mode to encourage group learning.

- Some virtual practice/learning by doing sessions can be arranged with the application of ICT for better understanding and raising the interest level in a technical course.

- Some voice-over PPTs slides should be provided because downloading the complete lecture will remain as an issue due to the availability of internet data/plan [31]

Although, social distancing and lockdown forced students to opt online mode from normal offline mode due to COVID-19 but most of them still favoured the offline mode especially for this course. Therefore, it is important to learn available technology deeply with due diligence to balance the situation of chaos and tension created by COVID-19. Also, government and institute must provide all support to facilitate teaching-learning activities irrespective of location, social class, ethnicity etc. to reduce their stress, fear and anxiety level and hence make teaching-learning more interesting. Lastly, a high degree of preparedness is required to quickly adapt all changes in the environment so as to adjust with any delivery mode.

\section{Declarations}

\section{Acknowledgement}

Authors are thankful to Dr Sita Ram Sharma, Chitkara University School of Engineering and Technology, Chitkara University, Himachal Pradesh 174103 (India) for his guidance and support during the 
compilation of this study.

\section{Disclosure of potential conflicts of interest}

There is no conflict of interest.

ETHICAL STATEMENT - Not applicable

CONSENT STATEMENT - Not applicable

\section{References}

[1] V. Singh and A. Thurman, "How Many Ways Can We Define Online Learning? A Systematic Literature Review of Definitions of Online Learning (1988-2018)," Am. J. Distance Educ., vol. 33, no. 4, pp. 289-306, 2019, doi: 10.1080/08923647.2019.1663082.

[2] K. Finch, D., Jacobs, "Online education: Best practices to promote learning.," in Proceedings of the Human Factors and Ergonomics 56th Annual Meeting., 2012, pp. 546-550, doi: $10.1177 / 1071181312561114$.

[3] N. Todorova and N. Bjorn-Andersen, "University Learning in Times of Crisis: The Role of IT," Account. Educ., vol. 20, no. 6, pp. 597-599, 2011, doi: 10.1080/09639284.2011.632913.

[4] ETGovernment, "Lockdown Impact: Government's e-learning platforms witness surge in subscribers.," https://government.economictimes.indiatimes.com/news/education/lockdown-impactgovernments-e-learning-platforms-witness-surge-in-subscribers/748708. 2020.

[5] I. Z. A. D. P. No, M. Piopiunik, L. Woessmann, M. Piopiunik, and G. Schwerdt, "DISCUSSION PAPER SERIES Skills, Signals, and Employability: An Experimental Investigation Skills, Signals, and Employability: An Experimental Investigation," no. 11283, 2018.

[6] S. Dhawan, "Online Learning: A Panacea in the Time of COVID-19 Crisis," J. Educ. Technol. Syst., vol. 49, no. 1, pp. 5-22, 2020, doi: 10.1177/0047239520934018.

[7] S. Gua, "Synchronous versus asynchronous online teaching of physics during covid-19 pandemic," Phys. Educ., vol. 55, no. 6, 2020.

[8] J. . Littlefield, "The Difference Between Synchronous and Asynchronous Distance Learning.," ThoughtCo, Aug. 27, 2020, thoughtco.com/synchronous-distance-learning-asynchronous-distancelearning-1097959. .

[9] S. Affouneh, S. Salha, and Z. N. Khlaif, "Designing Quality E-Learning Environments for Emergency Remote Teaching in Coronavirus Crisis," Interdiscip J Virtual Learn Med Sci, vol. 11, no. 2, pp. 1-3, 2020, doi: 10.30476/ijvlms.2020.86120.1033. 
[10] M. Kebritchi, A. Lipschuetz, and L. Santiague, "Issues and Challenges for Teaching Successful Online Courses in Higher Education," J. Educ. Technol. Syst., vol. 46, no. 1, pp. 4-29, 2017, doi: $10.1177 / 0047239516661713$.

[11] A. Balasopoulou et al., "Symposium Recent advances and challenges in the management of retinoblastoma Globe - saving Treatments," BMC Ophthalmol., vol. 17, no. 1, p. 1, 2017, doi: 10.4103/ijo.IJO.

[12] E. Liguori and C. Winkler, "From Offline to Online: Challenges and Opportunities for Entrepreneurship Education Following the COVID-19 Pandemic," Entrep. Educ. Pedagog., vol. 3, no. 4, pp. 346-351, 2020, doi: $10.1177 / 2515127420916738$.

[13] S. Agarwal and J. S. Kaushik, "Student's Perception of Online Learning during COVID Pandemic," Indian J. Pediatr., vol. 87, no. 7, p. 554, 2020, doi: 10.1007/s12098-020-03327-7.

[14] S. Abbasi, T. Ayoob, A. Malik, and S. I. Memon, "Perceptions of students regarding e-learning during covid-19 at a private medical college," Pakistan J. Med. Sci., vol. 36, no. COVID19-S4, pp. S57-S61, 2020, doi: 10.12669/pjms.36.COVID19-S4.2766.

[15] S. Singh, D. H. Rylander, and T. C. Mims, "Efficiency of Online vs. Offline Learning: A Comparison of Inputs and Outcomes," Int. J. Business, Humanit. Technol., vol. 2, no. 1, pp. 93-98, 2012, [Online]. Available: http://ijbhtnet.com/journals/Vol_2_No_1_January_2012/12.pdf.

[16] A. Martin, "How to Optimize Online Learning in the Age Coronavirus (COVID-19): A 5-Point for Guide for Educators," UNSW Newsroom, vol. 53, no. 9, pp. 1-30, 2020, doi: 10.1017/СB09781107415324.004.

[17] V.-M. Cojocariu, I. Lazar, V. Nedeff, and G. Lazar, "SWOT Anlysis of E-learning Educational Services from the Perspective of their Beneficiaries," Procedia - Soc. Behav. Sci., vol. 116, no. February 2015, pp. 1999-2003, 2014, doi: 10.1016/j.sbspro.2014.01.510.

[18] M. Parkes, S. Stein, and C. Reading, "Student preparedness for university e-learning environments," Internet High. Educ., vol. 25, no. January 2019, pp. 1-10, 2015, doi: 10.1016/j.iheduc.2014.10.002.

[19] T. Favale, F. Soro, M. Trevisan, I. Drago, and M. Mellia, "Campus traffic and e-Learning during COVID-19 pandemic," Comput. Networks, vol. 176, no. May, 2020, doi: 10.1016/j.comnet.2020.107290.

[20] G. Basilaia, "Replacing the Classic Learning Form at Universities as an Immediate Response to the COVID-19 Virus Infection in Georgia," Int. J. Res. Appl. Sci. Eng. Technol., vol. 8, no. 3, pp. 101-108, 2020, doi: 10.22214/ijraset.2020.3021.

[21] G. Di Pietro, "The academic impact of natural disasters: evidence from L'Aquila earthquake," Educ. Econ., vol. 26, no. 1, pp. 62-77, 2018, doi: 10.1080/09645292.2017.1394984. 
[22] K. Shiwaku and R. Shaw, "Disaster Prevention and Management: An International Journal Article information:," Disaster Prev. Manag. An Int. J., vol. 17, no. 2, pp. 183-198, 2008.

[23] T. J. Wilkinson, A. N. Ali, C. J. Bell, F. A. Carter, C. M. Frampton, and J. M. Mckenzie, "The impact of learning environment disruption on medical student performance," Med. Educ., vol. 47, no. 2, pp. 210213, 2013, doi: 10.1111/medu.12065.

[24] K. Ayebi-Arthur, "E-learning, resilience and change in higher education: Helping a university cope after a natural disaster," E-Learning Digit. Media, vol. 14, no. 5, pp. 259-274, 2017, doi:

$10.1177 / 2042753017751712$.

[25] W. R. R. Preedy V.R., Handbook of Disease Burdens and Quality of Life Measures. Springer, New York, NY, 2010.

[26] J. Holbeck, Rick \& Hartman, "Efficient Strategies for Maximizing Online Student Satisfaction: Applying Technologies to Increase Cognitive Presence, Social Presence, and Teaching Presence.," J. Educ. Online, vol. 15, 2018, doi: 10.9743/jeo.2018.15.3.6.

[27] C. Hewson, J. Charlton, and M. Brosnan, "Comparing Online and Offline Administration of Multiple Choice Question Assessments to Psychology Undergraduates: Do Assessment Modality or Computer Attitudes Influence Performance?," Psychol. Learn. Teach., vol. 6, no. 1, pp. 37-46, 2007, doi: 10.2304/plat.2007.6.1.37.

[28] J. Groen and Y. Herry, "The Online Evaluation of Courses: Impact on Participation Rates and Evaluation Scores," Can. J. High. Educ., vol. 47, no. 2, pp. 106-120, 2017.

[29] M. . Hollister, K.K. and Berenson, "Proctored versus unproctored online exams: Studying the impact of exam environment on student performance," Decis. Sci. J. Innov. Educ., vol. 7, no. 1, pp. 271-294, 2009.

[30] "COVID-19 INDIA as on: 06 October 2020, 08:00 IST (GMT+5:30):" https://www.mohfw.gov.in/ (accessed Oct. 06, 2020).

[31] A. O. Mohmmed, B. A. Khidhir, A. Nazeer, and V. J. Vijayan, "Emergency remote teaching during Coronavirus pandemic: the current trend and future directive at Middle East College Oman," Innov. Infrastruct. Solut., vol. 5, no. 3, pp. 1-11, 2020, doi: 10.1007/s41062-020-00326-7.

\section{Figures}




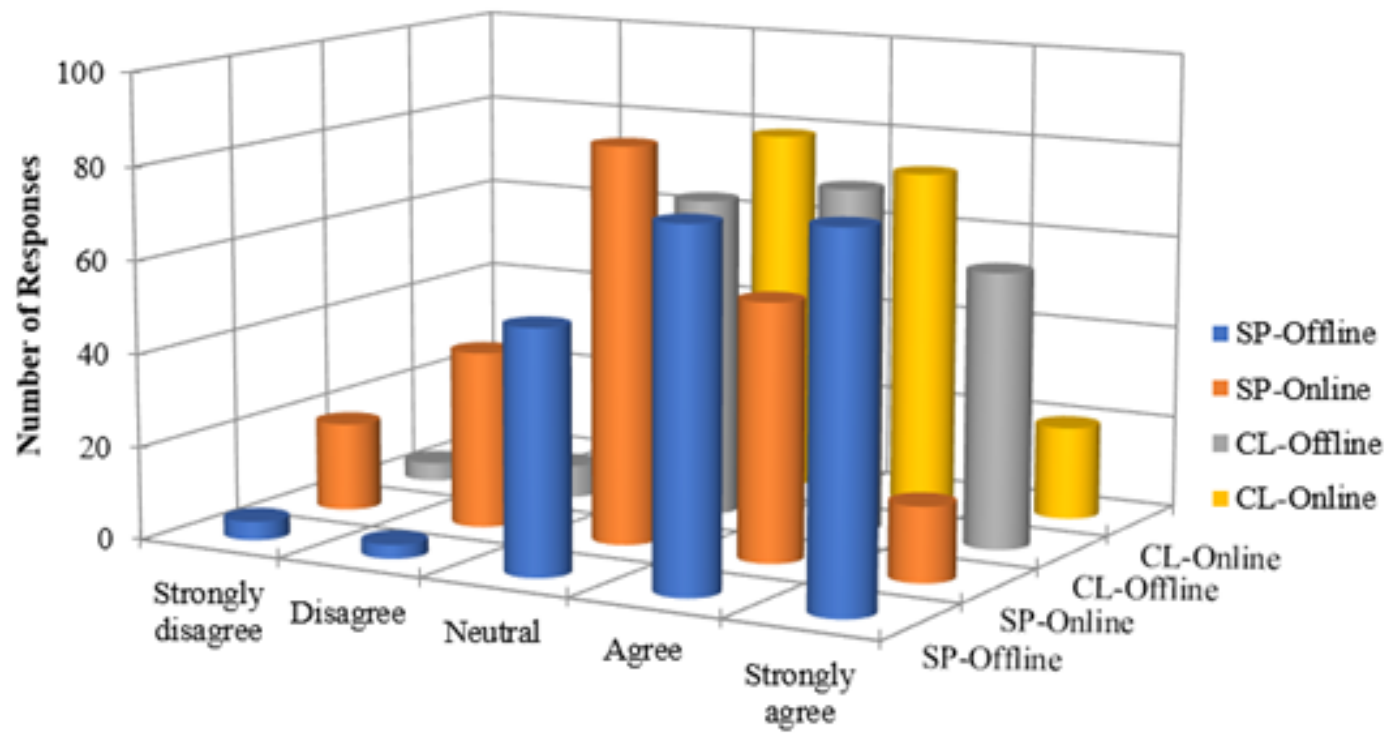

Five Point Scale

\section{Figure 1}

Responses of SP and their CL versus five-point scale [32] about online and offline mode of teaching.

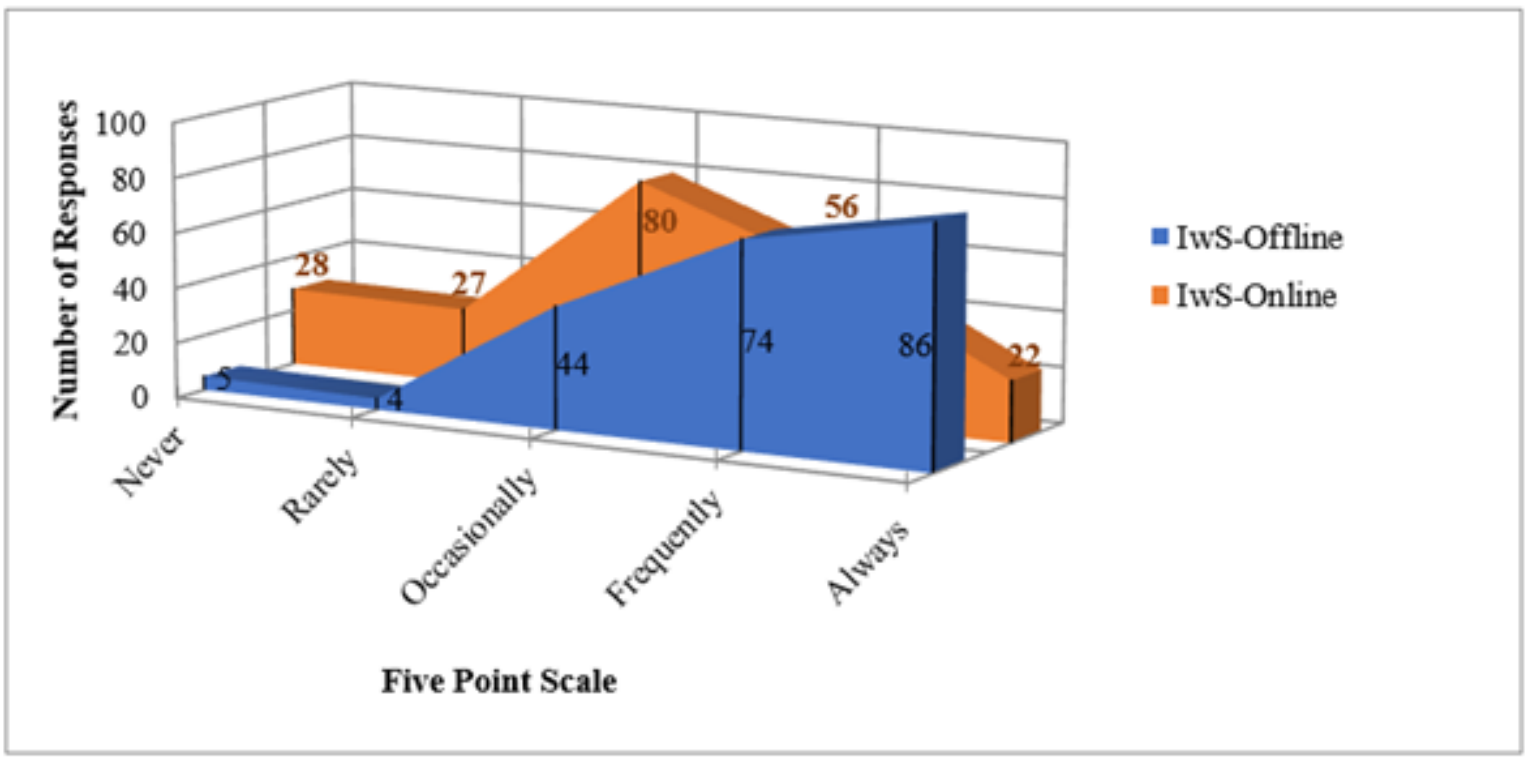

Figure 2

Responses of students related to IwS during online and offline mode of teaching. 


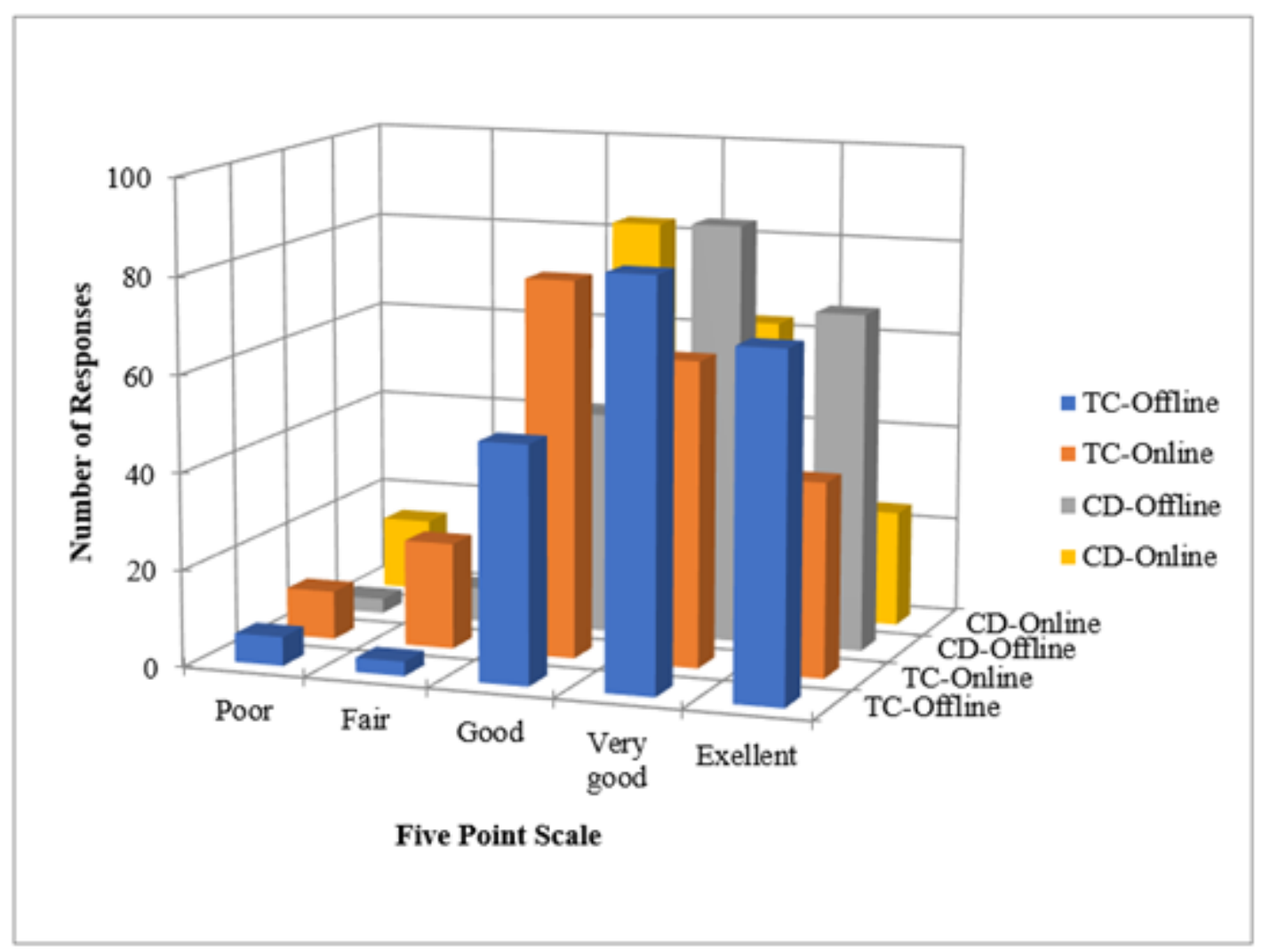

\section{Figure 3}

Responses of students related to TC and CD versus five point scale about online and offline mode of teaching .

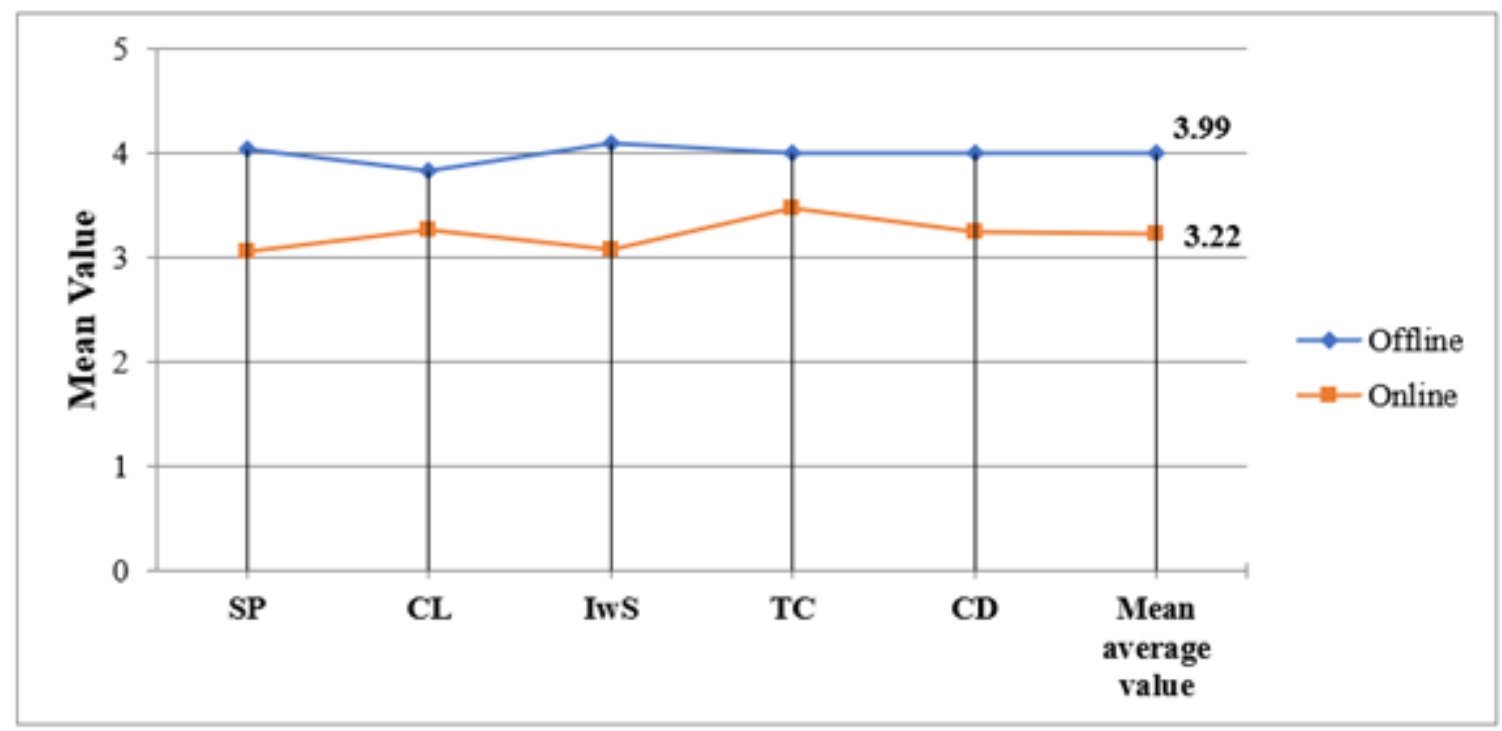

Figure 4

Mean response from 213 recorded responses based on five point scale corresponding to parameters mentioned over $\mathrm{X}$-axis related to offline versus online mode of teaching. 


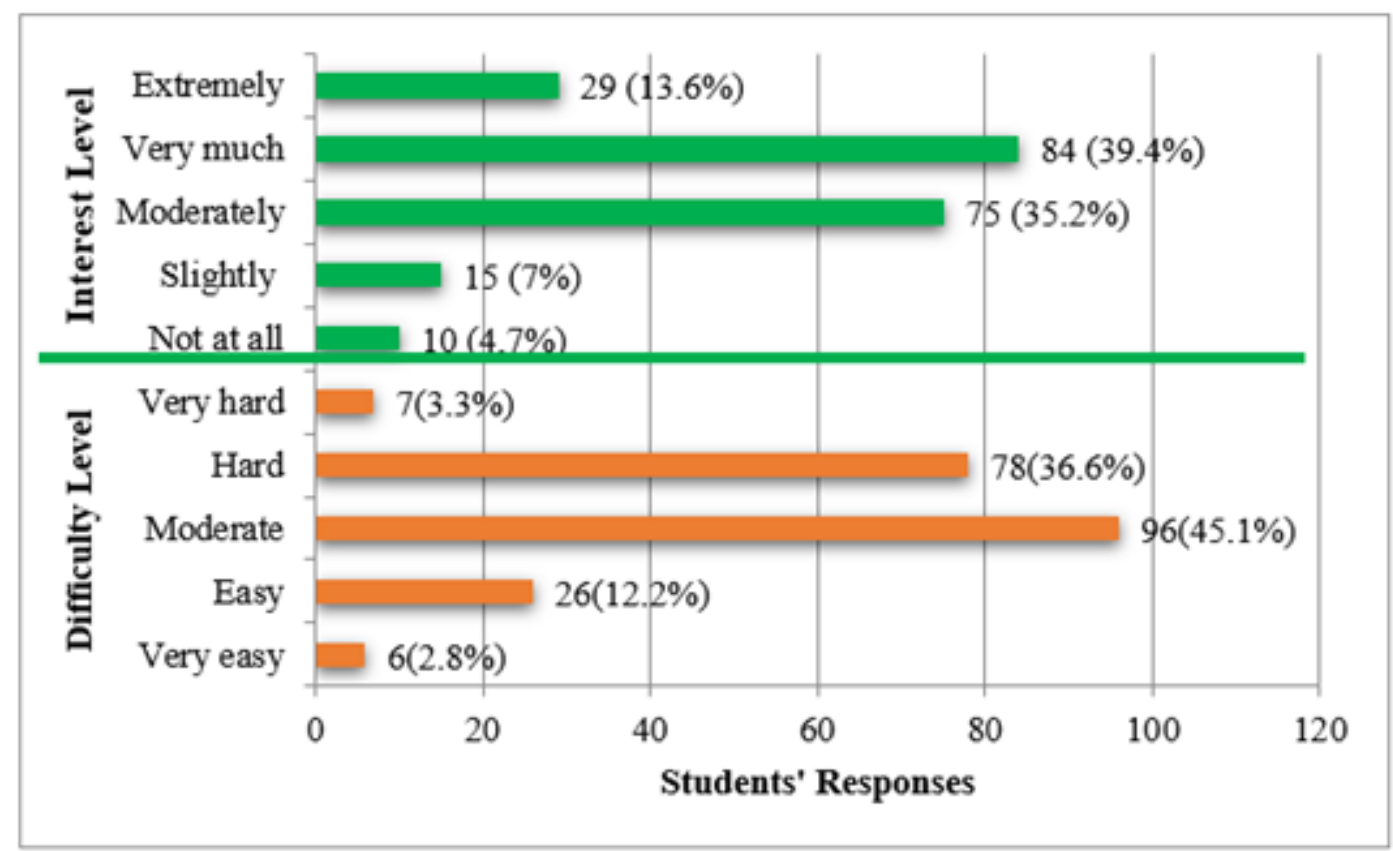

Figure 5

Responses of students related to level of interest (a) and difficulty (b) in learning Modern and Computational Physics course in general. 